\title{
INFLUENCE OF PHYSIOTHERAPY AND BALNEOTHERAPY IN PATIENTS WITH SPINAL DISC DISEASE
}

\author{
Antoaneta Dimitrova, Kristin Grigorova-Petrova, Daniela Lubenova, Milena Nikolova \\ National Sports Academy "Vassil Levski"
}

\begin{abstract}
Chronic spinal disc disease has a large socioeconomic impact on the health care system. A lot of researchers confirm that physiotherapy $(P T)$ is an effective choice of treatment for many patients.

The aim of the present study is to evaluate the combined effect of physiotherapy and balneotherapy thetreatment of lumbar disc disease and to compare the results with those obtained only after physiotherapy.

Twenty patients with lumbar disc disease in the chronic period, divided into two groups - experimental and control were studied. The experimental group did exercises in a thermal mineral pool and underwent a general PT program for ten days, while the control group had only general PT program for ten days. The general PT program was the same for both groups. Before and after the treatment the Schober test and the static part of the Kraus-Weber test were conducted.

We revealed significant positive changes in the lumbar flexibility, endurance and strength of the back muscles, mm. glutei, abdominal muscles and the hip flexors among the patients from the experimental group, objectified by the increased time to perform the static test positions of Kraus-Weber Test and Schober test.

We recommend our program with $P T$ and balneotherapy as appropriate when dealing with patients with chronic lumbar spine disease in balneological resorts and SPA hotels.
\end{abstract}

Key words: aquatic exercises, mineral pool, lumbar disc disease

\section{INTRODUCTION}

Disc disease is a very common disease, as in the last half of the $20^{\text {th }}$ century it reached epidemic proportions mostly in the developed countries like the USA, Great Britain, Germany, Netherlands and others. Disc disease disables patients and creates inconvenience in the performance of their daily activities. About $30 \%$ of the sufferers develop a chronic pain, which leads to a costly medical treatment and losses in economy. The most common cause of degenerative spinal diseases is the intervertebral disc changes associated with formation of spinal disc herniations, protrusions, intervertebral joints' changes, osteophytes, spondylolisthesis and other changes in the spine structures. Risk factors are heavy physical work, bad static posture, weak con- nective tissue, gender, age, and others. Over 350,000 Bulgarians consult with a neurologist due to lower back, lumbar spine, and neck pain annually. Most often the pain is provoked by an incorrect posture, sudden movement, or lifting heavy objects. The pain is strong and leads to a significant disability, inability to get out of bed, and difficulty in performing everyday activities (Lubenova, 2011; Lubenova et al., 2017; Cassidi et al., 1998).

The wide distribution and severity of disc disease are a good reason to conduct extensive research on the demand and application of proper treatment. Complementary therapies like aquatic exercises, SPA and balneotherapy are used by patients with low back pain, muscle weakness and decreased range of motion in lumbar spine. They are used particularly in 
European countries and the costs are, at least in part, reimbursed by health insurance systems (e.g. Germany). In contrast to hydrotherapy, which employs normal tap water, balneotherapy is defined as the use of baths containing thermal mineral waters from natural springs at a temperature of at least $28^{\circ} \mathrm{C}$ and with a mineral content of at least $1 \mathrm{~g} / \mathrm{l}$. SPA rituals employs physiotherapeutic interventions at a spa resort (Pittler et al., 2006; Bender et al., 2005).

Few countries in Europe could outrival Bulgaria's SPA and balneological resources with its plenitude and diversity of thermal mineral waters. There are more than 550 known sources with 1,600 springs. Waters with low mineral content are prevailing $-66.7 \%$ of the springs, as opposed to $14.4 \%$ with higher mineral content and $17.9 \%$ that are naturally carbonated. The most famous thermal springs in the Balkan Mountains are in the regions of Hissarya, Varshets, Bankya, Gorna Banya and many others (Petrova, 2009).
We studied the combined influence of physiotherapy and balneotherapy on the functional status of patients suffering from chronic lumbar disc disease. The results obtained were compared with the results achieved after applying only physiotherapy. The functional status of each patient was monitored and the effect of the applied treatment was reported.

The purpose of the treatment was to restore the function of the affected lumbar spine and to prevent recurrence of pain and disability.

\section{METHODS}

Twenty patients with lumbar disc disease in the chronic period, divided in two groups, were monitored. The experimental group included 10 patients ( 5 women and 5 men, average age of 52.47 years), while the control group consisted of 10 patients ( 7 women and 3 men, average age of 52.79 years). The clinical characteristics of the studied contingent are presented in Table 1. Patients in the two groups do not differ by sex, age, body weight and disease duration.

Table 1. Clinical characteristics of the patients

\begin{tabular}{lll}
\hline Parameter & $\begin{array}{l}\boldsymbol{E G}(\boldsymbol{n}=\mathbf{1 0}) \\
\boldsymbol{X} \pm \boldsymbol{S D}\end{array}$ & $\begin{array}{l}\boldsymbol{C G}(\boldsymbol{n}=\mathbf{1 0}) \\
\boldsymbol{X} \pm \boldsymbol{S D}\end{array}$ \\
\hline $\begin{array}{l}\text { Gender } \\
\text { women/men }\end{array}$ & $5 / 5$ & $7 / 3$ \\
Average age (years) & $52,5 \pm 2,5$ & $52,8 \pm 3,8$ \\
Duration of the disease (years) & $2 \pm 15$ & $1 \pm 10$ \\
Body weight (kg) & $80,8 \pm 2,8$ & $83,3 \pm 3,1$ \\
\hline$X-$
\end{tabular}

$X$ - mean values; SD-standard deviation; $E G$ - experimental group; CG - control group

For the purposes of the study the lumbar flexion and the muscle strength of monitored patients was evaluated twice at the beginning of the treatment and on the $10^{\text {th }}$ day. The static part of Kraus-Weber test was used, modified and described in detail in Bulgarian (Milcheva, 1991). It included nine isometric test positions, which the patients retained according to their capabilities. The retention time was measured in seconds. Increasing the values of the nine test positions provided information about the strength and endurance of the muscles forming the muscle physiological corset. The Schober's test assesses the ability of lumbar spine flexion. A point is identified at the level of vertebra L5. A mark is made $5 \mathrm{~cm}$ below and 10 
$\mathrm{cm}$ above that point. The patient bends at the waist to full forward flexion. The distance between the two marks is measured; if $<20 \mathrm{~cm}$, it indicates limitation of lumbar flexion (Bender et al., 2014).

All patients involved in the study were treated in Specialized Hospital for Rehabilitation - town of Hissarya. The patients from the experimental group did exercises in a mineral pool and underwent a general PT program for ten days, while the patients from the control group underwent only general PT program for ten days. The patients from the experimental group and from the control group performed PT 45-minute sessions every day and moderate intensity program for ten days. Therapeutic exercises in the PT sessions were the same for the two studied groups.

General physiotherapy program for the patients from the experimental and control groups

The exercises for both groups in the warmup part of the physiotherapy sessions included 10-minute stretching and breathing exercises. The patients did stretching exercises $5-10$ times every day. Postisometric relaxation in the presence of muscle imbalance and increased muscle tone of $\mathrm{m}$. triceps surae, $\mathrm{m}$. illiopsoas, $\mathrm{m}$. quadratus lumborum, m. piriformis, hip joint adductors and others were applied. The postisometric relaxation was included in order to provide a pain reliever effect due to the influence on the segmental reflex arc through the nervereflection mechanisms.

In the main part of the physiotherapy sessions different body positions like lying, hands and knees, prone and standing positions were used. Various exercises were included to strengthen the weak muscles (back, abdomen and gluteal muscles) with Pilates, isometric exercises for spine extensors, Thera-band exercises and core stabilization exercises. We believe that senso-motor control plays much more important role than the strength or endurance of the trunk muscles. To achieve greater changes in the motor control, equilibrium and functional training by gradual progression from stable to unstable support we included fit ball, exercises on foam surfaces (to stimulate the stability and balance on the trunk muscles), transfers from sitting to standing, combined with movements with increasing resistance. The lumbar motor control exercises for $\mathrm{m}$. transversus abdominis, lumbar multifidus and pelvic floor muscles were applied to improve spinal mechanical support. Proprioceptive neuromuscular facilitation was used to facilitate the neuromuscular response by stimulating proprioceptors through postural stimuli, to achieve improvement in the posture, equilibrium, coordination and functional activity of the patients. To maintain and improve mobility, other exercises such as cat stretch, sidebending to the wall, bottom walking and lower trunk rotation were applied.

In the cool down part of the physiotherapy session breathing exercises and autogenic relaxation for 5-7 minutes were applied. To achieve muscle relaxation, breathing exercises like deep diaphragmatic breathing with slow counting, pursed lips breathing, and chest breathing exercises were included.

\section{Balneotherapy for the patients from the experimental group}

The difference between the two groups is that the patients from the experimental group performed exercises in the thermal mineral pool with pool noodles. The balneotherapy sessions were performed twice daily for ten days in the mineral water from 15 to 25 minutes. The temperature of the water was $37,5^{\circ}$ 
Table 2. Changes in the muscle strength of monitored patients

\begin{tabular}{|c|c|c|c|}
\hline Test positions & Group & $\mathrm{X}_{1} \pm \mathrm{SD}$ & $\mathrm{X}_{2} \pm \mathrm{SD}$ \\
\hline \multirow{3}{*}{ Test of the hipflexor and abdominal muscles } & EG & $18.0 \pm 6.1$ & $21.0 \pm 6.9^{\star * *}$ \\
\hline & CG & $19.0 \pm 4.8$ & $21.3 \pm 5.2^{\star *}$ \\
\hline & $\mathrm{p}$ & 0.6 & 0.9 \\
\hline \multirow{3}{*}{ Test of the abdominal muscles } & EG & $17.8 \pm 6.8$ & $21.4 \pm 7.1^{\star \star}$ \\
\hline & CG & $16.1 \pm 6.5$ & $19.4 \pm 6.9^{* * *}$ \\
\hline & $\mathrm{p}$ & 0.6 & 0.5 \\
\hline \multirow{3}{*}{ Test of the upper back muscles } & EG & $13.1 \pm 5.1$ & $16.2 \pm 4.6^{\star * *}$ \\
\hline & CG & $13.8 \pm 5.4$ & $15.3 \pm 6.3^{\star \star}$ \\
\hline & $\mathrm{p}$ & 0.7 & 0.7 \\
\hline \multirow{3}{*}{ Test of the lower back and sciatic muscles } & EG & $9.2 \pm 3.7$ & $11.6 \pm 4.1^{\star * *}$ \\
\hline & CG & $11.4 \pm 3.5$ & $11.9 \pm 3.6$ \\
\hline & $\mathrm{p}$ & 0.1 & 0.8 \\
\hline \multirow{3}{*}{ Test of the hipflexor } & EG & $9.7 \pm 6.7$ & $11.9 \pm 9.3^{\star}$ \\
\hline & CG & $6.5 \pm 5.1$ & $8.60 \pm 5.1^{\star \star}$ \\
\hline & $\mathrm{p}$ & 0.2 & 0.3 \\
\hline \multirow{3}{*}{ Test of the left $\mathbf{m}$. quadratus lumborum } & EG & $7.7 \pm 2.7$ & $9.2 \pm 2.4^{\star *}$ \\
\hline & CG & $9.6 \pm 3.8$ & $12 \pm 4.2^{\star *}$ \\
\hline & $\mathrm{p}$ & 0.2 & 0.1 \\
\hline \multirow{3}{*}{ Test of the right $\mathrm{m}$. quadratus lumborum } & EG & $8.2 \pm 3.0$ & $10.2 \pm 2.2^{\star *}$ \\
\hline & CG & $9.4 \pm 4.6$ & $11.3 \pm 4.2^{\star \star}$ \\
\hline & $\mathrm{p}$ & 0.5 & 0.4 \\
\hline \multirow{3}{*}{ Test of the abdominal muscles and hipflexor without fixation } & EG & $13.5 \pm 5.2$ & $15.6 \pm 4.8^{*}$ \\
\hline & CG & $9.2 \pm 4.2$ & $10.1 \pm 5.1$ \\
\hline & $\mathrm{p}$ & 0.05 & 0.02 \\
\hline \multirow{3}{*}{$\begin{array}{l}\text { Test of the upper and lower back muscles } \\
\text { and thes ciatic muscles without fixation }\end{array}$} & EG & $3.9 \pm 1.7$ & $4.9 \pm 1.9^{*}$ \\
\hline & CG & $6.7 \pm 3.1$ & $6.7 \pm 2.5$ \\
\hline & $\mathrm{p}$ & 0.02 & 0.09 \\
\hline
\end{tabular}

$X_{1}, X_{2}-$ mean values before and after the treatment; $S D$ - standard deviation; ${ }^{* * *} p<0.001,{ }^{* *} p<0.01,{ }^{*} p<0.05-$ significant differences for each group in the course of treatment compared to the baseline parameters; $p$ - significant differences between the experimental group (EG) and control group (CG)

The analysis of the results at the beginning of the treatment showed a decrease in the muscle strength caused by the pain that prevented the patients from retaining the test positions for a continuous period of time. Restrictions were most pronounced in the back, abdomen and seat muscles, as well as in the hip flexors. After applying physiotherapy a significant improvement was observed in the muscle strength of the patients in the experimental group. The ten-day physiotherapy of the control group also had a positive impact, according to the monitored indicators, but in terms of absolute values it was weaker compared to the values of the patients in the experimental group. On the $10^{\text {th }}$ day no significant improvement was observed in three test positions, objectifying the strength of upper and lower back muscles, seat and abdomen muscles, as well as hip flexors. The results of changes in the muscle strength at the end of the treatment of the experimental and control group are presented in Figure 1. 


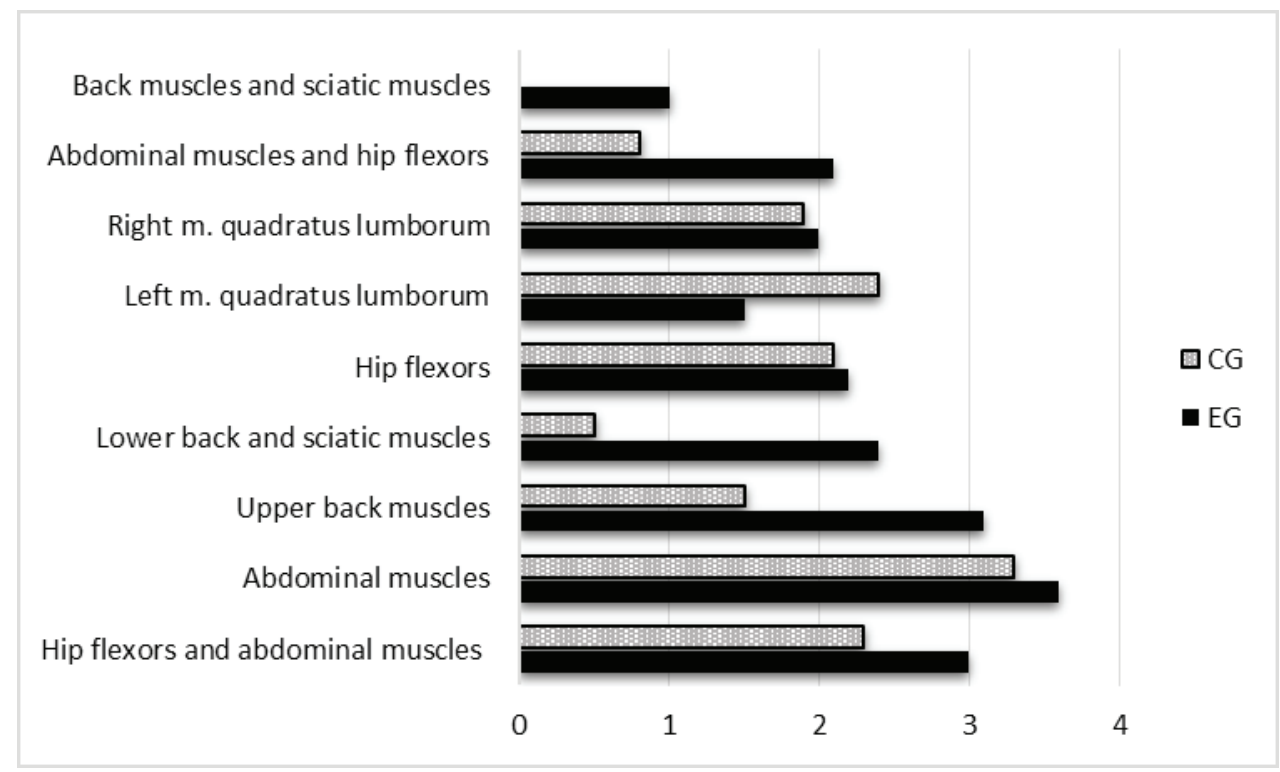

Figure 1. Changes in the average values of muscle strength, according to Kraus-Weber test, presented as a difference between the background values and obtained results at the end of the treatment in the experimental group (EG) andcontrol group (CG)

The comparison between the groups in the course of treatment indicated better results in the absolute mean values of the monitored parameters of the patients in the experimental group at the end of the treatment regarding the strength of back and gluteal muscles, abdomen muscles and hip flexors, which is associated with the patients' better functional status of the spine, positive change in the posture and walking pattern.

These positive changes are associated with the significant improvement in spine mobility, as measured with the Schober's test (Table 3).

Table 3. Changes in the lumbar mobility of the patients

\begin{tabular}{lllll}
\hline Parameter & Group & $\mathbf{X}_{1} \pm \mathbf{S D}$ & $\mathbf{X}_{2} \pm \mathbf{S D}$ & $\mathbf{P}$ \\
\hline \multirow{3}{*}{ Schober test $(\mathrm{cm})$} & EG & $13,2 \pm 0,7$ & $16,3 \pm 0,6$ & 0,003 \\
& CG & $13,5 \pm 0,9$ & $14,1 \pm 0,9$ & 0,15 \\
& $\mathrm{p}$ & 0,4 & 0,01 & \\
\hline
\end{tabular}

$X_{1} X_{2}-$ mean valuesbefore and after the treatment; SD-standard deviation; $p<0.001, p<0.01, p<0.05-$ significant differences for each group in the course of treatment compared to the baseline parameters; $p$-significant differences between the experimental group (EG) and control group (CG)

There were no significant differences between the two groups before the treatment. A statistically significant improvement in the patients from the experimental group was observed $(p<0.01)$ after the treatment. The lumbar flexibility increased with $3,1 \mathrm{~cm}$ in the experimental group and $0,6 \mathrm{~cm}$ for the patients of the control group.

\section{DISCUSSION}

Thermal waters in Bulgaria are infused with huge variety of minerals with predominance of radon, silicic acid, fluorine,calcium, sodium, and sulphates whose health-enhancing benefits are exacerbated by the water's high temperature. The conditions that have been especially ameliorated or cured outright 
by exposure to thermal water are neurological, orthopedic, different internal diseases and many others disorders. There are more than 100 balneo resorts in Bulgaria which incorporate thermal water into their physician-supervised rehabilitation programs (Lubenova et al., 2017; Izov et al., 2017; Petrova, 2009).

In a recent review article the authors provide an evidence-based summary on the effectiveness of aquatic exercises and balneotherapy in the treatment of musculoskeletal conditions such as low back pain, osteoarthritis, fibromyalgia and rheumatoid arthritis. The purpose of balneotherapy is to help patients to perform their physiotherapy program outside the pool to recover and restore their lost functions optimally. Over 30 years of research demonstrates that exercises in general, and specifically aquatic exercises, are beneficial for reducing pain and disability in many musculoskeletal conditions. Balneotherapy might be beneficial, but a highquality research should be conducted on the effects of balneotherapy and aquatic exercises on specific patient groups (Verhagen et al., 2012).

A meta-analysis of randomized control trials showed the beneficial effect of thermal mineral water compared with tap water. Both the clinical indices and the quality of life parameters improved significantly in the active treatment groups. The use of tap water is a rarity in the literature on the evaluation of mineral waters for low back pain. A study, repeated after a year period, revealed that the analgesic consumption was significantly lower among the patients from the balneotherapy group compared to the values for those from the control group who drank tap water (Bender et al., 2014; Gaal et al., 2008; Kamioka et al., 2010; Kulisch et al., 2009; Tefner et al., 2012).

Balneotherapy has long been used as a traditional treatment in Hungary because the country is rich in thermal mineral waters. The majority of the published papers focus on balneotherapy for musculoskeletal disorders
(Bender et al., 2014).

The exercises performed in water strengthen weak muscles due to the natural resistance that exists during balneotherapy and underwater physical exercises (Petkov, 2007; Petrova, 2009; Becker et al, 2009; Kurutz et al., 2003).

Training in water is performed against resistance, which improves balance, muscle tone, muscle strength and sensation (Becker et al., 2009; Kaneda et al., 2008).

It has been proven that aquatic environment has the advantage compared to dry land exercises because the patients do not get fatigued after underwater physical exercises, which prevent the occurrence of pain after the procedures (Kaneda et al., 2008).

Noticeable changes are found in the posture of patients; they begin to keep their spine in the correct position, while sitting, standing and walking. The activities of daily life are not difficult for them and they begin to do them without needing help any more (Kurutz et al., 2003; Waller et al., 2009).

These are the main aspects in which physiotherapy and balneotherapy have a beneficial effect on the patients with disc disease. The exercises in the thermal mineral pool in the progressive intensity increase the range of movement, muscle strength and lumbar flexibility, reducing the pain and stiffness in the affected parts of the body (Tasheva, 2007; Petrova, 2009).

Therapeutic aquatic exercises in mineral pool might have a beneficial effect, however, no better than other interventions. There was sufficient evidence to suggest that therapeutic aquatic exercise was potentially beneficial to patients suffering from chronic disk disease. There is further need for high-quality trials to evaluate the feasibility of therapeutic aquatic exercise in clinical settings. The application of physiotherapy for lumbar disc disease in the practice should not be ignored because it gives positive results and is well-tolerated by the patients. Aquatic activities are more interesting for the 
patients and improve their psycho-emotional tone (Waller et al., 2009).

The current study shows that the application of physiotherapy and balneotherapy sessions in the EG significantly improved the muscle strength and lumbar flexibility of the patients, whereas the routine physiotherapy methods applied to the control group had a less positive effect without significant changes in the strength of the back and seat muscles, abdomen muscles and hip flexors.

\section{CONCLUSION}

The study revealed that the combination of physiotherapy and balneotherapy procedures has a positive effect on the muscle strength and lumbar flexibility of patients with chronic lumbar disc disease. No negative changes or adverse reactions were observed.

\section{REFERENCES}

Becker, B., Hildenbrand, K., Whitcomb, B., Sanders, J. (2009). Biophysiologic effects of warm water immersion. Int. J. Aquatic Res. Educ., No.3, pp. 24-37.

Bender, T., Karagu"lle, Z., Balint, G., Gutenbrunner, C., Balint, P., Sukenik, S. (2005). Hydrotherapy, balneotherapy, and spa treatment in pain management. Rheumatol In., No.25, pp. 220-224.

Bender, T., Bálint, G., Prohászka, Z. et al. (2014). Evidence-based hydro- and balneotherapy in Hungary - a systematic review and meta-analysis. Int J Biometeorol., Vol 58 No.3, pp. 311-323 https://doi.org/10.1007/s00484013-0667-6

Cassidi, D., Wedge, J. (1998). The epidemiology and natural history of low back pain and spinal degeneration in managing low back pain. Churchill Livingstone, New York

Gaal, J., Varga, J., Szekanecz, Z., Kurkó, J., Ficzere, A., Bodolay, E., Bender, T. (2008). Balneotherapy in elderly patients: effect on pain from degenerative knee and spine conditions and on quality of life. Isr Med Assoc J.,
No.10, pp. 365-369

Izov, N., Maznev, I., Nikolova, M., Vasileva, D. (2017). Effect of swimming and physiotherapy in patients with nephrolithiasis. Journal of Applied Sports Sciences, No.1, pp. 84-89

Kamioka, H., Tsutani, K., Okuizumi, H., Mutoh, Y., Ohta, M., Handa, S., Okada, S., Kitayuguchi, J., Kamada, M., Shiozawa, N., Honda, T. (2010). Effectiveness of Aquatic Exercise and Balneotherapy: A Summary of Systematic Reviews Based on Randomized Controlled Trials of Water Immersion Therapies. J Epidemiol, No.20, pp. 2-12

Kaneda, K., Sato, D., Wakabayashi, H., Hanai, A., Nomura, T. (2008). A comparison of the effects of different water exercise programs on balance ability in elderly people. $J$. Aging Physic Activity, No.16, pp. 381-392.

Kulisch, A., Bender, T., Németh, A., Szekeres, L. (2009). Effect of thermal water and adjunctive electrotherapy on chronic low back pain: a double-blind, randomized, follow-up study. J Rehabil Med, No.41, pp. 73-79

Kurutz, M., Bene, E., Lovas, A. (2003). In vivo deformability of human lumbar spine segments in pure centric tension, measured during traction bath therapy. Acta Bioeng. Biomech., No.5, pp.67-92.

Lubenova, D. (2011). Physiotherapy in Nervous and Mental Diseases. Betaprint Petrov and Co., Sofia

Lubenova, D., Bizheva, Ts., Izov, N., Maznev, I., Dimitrova, A. (2017). Principles of modern physiotherapy after surgical treatment of lumbar spine pain (review article). Proceeding book of the International Congress “Applied Sports Sciences”, pp.513-518

Milcheva, D. (1991). Methods for Diagnostics and Measurement of Healing Gymnastics. National Sport Academy, Sofia

Petkov, I. (2007). Basics of Physiotherapy. Tip-Top Press, Sofia

Petrova, T. (2009). The Big Book of SPA Water Code. Kolchida, Sofia 
Pittler, M., Karagülle, M.Z., Karagülle, domized controlled, single-blind, follow-up M., Ernst, E. (2006). Spa therapy and balneotherapy for treating low back pain: meta-analysis of randomized trials. Rheumatology, Vol 45 No. 7, pp. 880-884 https://doi.org/10.1093/ rheumatology/kel018

Tasheva, R. (2007). SPA\&wellness -sŭshtnost i prilozhenie, Meditsina i sport, Vol 1, pp. 16-20.

Tefner, I., Németh, A., Lászlófi, A., Kis, T., Gyetvai, G., Bender, T. (2012). The effect of spa therapy in chronic low back pain: a ranstudy. Rheumatol Int., No.32, pp. 3163-3169

Verhagen, A., Cardoso, J., Bierma-Zeinstra, S. (2012). Aquatic exercise \& balneotherapy in musculoskeletal conditions. Clinical Rheumatology, Vol 26 No. 3, pp. 335-343 https://doi.org/10.1016/j.berh.2012.05.008

Waller, B., Lambeck, J., Daly, D. (2009). Therapeutic aquatic exercise in the treatment of low back pain: a systematic review. Clinical Rehabilitation, Vol 23 No.1, pp. 3-14

\section{Corresponding author:}

Antoaneta Dimitrova Department of "Physiotherapy and Rehabilitation" National Sports Academy "Vassil Levski" Studentski grad, 21, Acad. Stefan Mladenov str. Sofia 1700, Bulgaria E-mail: tonialllex@yahoo.com 